\title{
Second-Line Tests in the Diagnosis of Adrenocorticotropic Hormone-Dependent Hypercortisolism
}

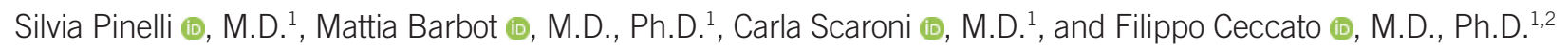 \\ ${ }^{1}$ Endocrinology Unit, Department of Medicine (DIMED), University-Hospital of Padova, Padova, Italy; ${ }^{2}$ Department of Neuroscience DNS, University of \\ Padova, Padova, Italy
}

Cushing's syndrome (CS) is a rare disease caused by chronic and excessive cortisol secretion. When adrenocorticotropin hormone (ACTH) is measurable, autonomous adrenal cortisol secretion could be reasonably ruled out in a differential diagnosis of CS. ACTH-dependent CS accounts for $80 \%-85 \%$ of cases and involves cortisol production stimulated by uncontrolled pituitary or ectopic ACTH secretion. Pituitary adenoma is not detected in up to one-third of cases with pituitary ACTH secretion, whereas cases of CS due to ectopic ACTH secretion may be associated with either malignant neoplasia (such as small cell lung carcinoma) or less aggressive neuroendocrine tumors, exhibiting only the typical symptoms and signs of CS. Since the differential diagnosis of ACTH-dependent CS may be a challenge, many strategies have been proposed. Since none of the available tests show 100\% diagnostic accuracy, a step-by-step approach combining several diagnostic tools and a multidisciplinary evaluation in a referral center is suggested. In this review, we present a clinical case to demonstrate the diagnostic work-up of ACTH-dependent CS. We describe the most commonly used dynamic tests, as well as the applications of conventional or nuclear imaging and invasive procedures.

Key Words: Cushing's syndrome, Pituitary adenoma, Ectopic ACTH secretion, Differential diagnosis

\author{
Received: September 19, 2020 \\ Revision received: November 17, 2020
}

Accepted: May 17, 2021

\section{Corresponding author:}

Filippo Ceccato, M.D., Ph.D.

Endocrinology Unit, Department of

Medicine (DIMED), University-Hospital of

Padova, Via Ospedale Civile, 105, Padova

35128, Italy

Tel: +39-049-821-1323

Fax: +39-049-657-391

E-mail: filippo.ceccato@unipd.it

\section{(i) (3)}

(c) Korean Society for Laboratory Medicine

This is an Open Access article distributed under the terms of the Creative Commons Attribution Non-Commercial License (https://creativecommons.org/licenses/by-nc/4.0) which permits unrestricted non-commercial use, distribution, and reproduction in any medium, provided the original work is properly cited.

\section{INTRODUCTION}

Endogenous Cushing's syndrome (CS) is caused by excessive and unregulated cortisol secretion [1, 2]. CS is a rare disease; however, its signs and symptoms are common among patients assessed for hypertension, metabolic syndrome, diabetes, mood disorders, or osteoporosis [3-5]. Adrenocorticotropin hormone (ACTH)-dependent CS accounts for $80 \%-85 \%$ of all CS cases. Excessive ACTH secretion is due to a pituitary adenoma (termed Cushing's disease, $C D$ ) or to paraneoplastic ectopic ACTH secretion (EAS) [6, 7]. Adrenal CS (ACTH-independent, 15\%-20\% of cases) is secondary to the autonomous cortisol secretion by a benign lesion (usually adenoma, as primary micro- or macronod- ular adrenal hyperplasia is extremely rare) or a malignant cortisol-secreting carcinoma [8].

After the initial diagnosis of CS, the mainstay of a differential diagnosis is measurement of the basal unstimulated morning ACTH level to determine whether or not the CS is ACTH-dependent [1, 9]. However, commercially available ACTH immunoassays may be imprecise for patients with reduced ACTH levels $(<4.4 \mathrm{pmol} / \mathrm{L})$; in such cases, a dynamic test is indicated to check for neuroendocrine responsiveness and exclude $\mathrm{ACTH}$ independent CS $[6,8,10]$.

As the differential diagnosis of ACTH-dependent CS may be a challenge, many diagnostic strategies have been proposed; however, none of the currently available tests shows 100\% diagnos- 
tic accuracy [3, 6, 7]. In clinical practice, some patients with confirmed CD exhibit equivocal and discordant results to dynamic tests, and it is not uncommon for some EAS cases to present as pituitary corticotropinoma. Imaging is not always helpful, because gadolinium (Ga)-enhanced magnetic resonance imaging (MRI) can detect pituitary tumors in roughly $60 \%-70 \%$ of patients with $\mathrm{CD}$, and incidental pituitary lesions have been reported in the general population, including in a minority of patients with EAS [11]. Neuroendocrine tumors may be difficult to localize, and approximately $20 \%$ of ACTH-secreting neoplasms remain occult, even when using the most accurate and sophisticated imaging techniques [12].

The need for methods to effectively distinguish between CD and EAS is based on the clinical observation that ACTH-secreting neuroendocrine tumors can cause CS that is often clinically and biochemically indistinguishable from CD. Many of these tumors (particularly bronchial carcinoids) remain occult to specific imaging techniques for many years. Similarly, CD cases with a negative MRI finding (estimated up to $30 \%$ ) can also be considered to be "occult." Notably, the outcome after pituitary surgery and the subsequent recurrence rate in cases of "occult CD" are similar to those of cases with a positive MRI finding [13, 14].

In this article, we provide an updated review of the literature regarding the differential diagnosis of $\mathrm{ACTH}$-dependent CS in the context of a case report.

\section{CORTICOTROPIN-RELEASING HORMONE (CRH) TEST}

The $\mathrm{CRH}$ test is used for the differential diagnosis of ACTH-de- pendent CS. The rationale is based on the assumption that $C D$ originates from well-differentiated pituitary corticotroph adenomas, which express $\mathrm{CRH}$ receptors and have the cellular constituents necessary to respond to $\mathrm{CRH}$. By contrast, EAS tumors are derived from non-pituitary tissues and generally do not respond to $\mathrm{CRH}$. However, some cases of ectopic ACTH-producing tumors can respond to $\mathrm{CRH}$, leading to false-positive results [15].

The $\mathrm{CRH}$ test is performed by injecting $1 \mu \mathrm{g} / \mathrm{kg}$ or $100 \mu \mathrm{g}$ synthetic ovine or human $\mathrm{CRH}$ intravenously, and collecting blood samples for cortisol and ACTH measurements before ( -15 minutes and immediately before) and after the injection until 120 minutes (usually at 15, 30, 45, 60, 90, and 120 minutes). However, there is no consensus on the criteria for interpreting the response to a $\mathrm{CRH}$ test. Variability in interpretation depends on the type of CRH used (human or ovine), biochemical parameters evaluated (cortisol and/or ACTH peak, or percent increase above baseline), and time points considered [6, 16]. Human $\mathrm{CRH}$ has qualitatively similar properties to ovine $\mathrm{CRH}$ and may provide the same diagnostic accuracy with regard to the ACTH response, whereas ovine $\mathrm{CRH}$ is considered to be superior in evaluation of the cortisol response [17, 18].

According to Ritzel, et al. [22], applying the commonly used cut-off value of a $30 \%$ rise in cortisol and $50 \%$ rise in $\mathrm{ACTH}$, the $\mathrm{CRH}$ test shows $78 \%$ sensitivity and $78 \%$ specificity for cortisol, and $83 \%$ sensitivity and $89 \%$ specificity for ACTH. These data are similar to those from previous studies considering a similar cut-off (Table 1) [19-21]. Based on the ROC curve, Ritzel, et al. [22] identified that an increase in ACTH $\geq 43 \%$ at 15 minutes after $\mathrm{CRH}$ injection was the strongest predictor for $\mathrm{CD}$, with $83 \%$ sensitivity and $94 \%$ specificity. In our previous case series, the

Table 1. Diagnostic accuracy of the $\mathrm{CRH}$ test

\begin{tabular}{|c|c|c|c|c|c|c|c|}
\hline Reference & N patients & $\begin{array}{c}\text { Cortisol rise } \\
\text { (\% above basal) }\end{array}$ & $\begin{array}{l}\text { Sensitivity } \\
(\%)\end{array}$ & $\begin{array}{l}\text { Specificity } \\
(\%)\end{array}$ & $\begin{array}{c}\text { ACTH rise } \\
\text { (\% above basal) }\end{array}$ & $\begin{array}{l}\text { Sensitivity } \\
(\%)\end{array}$ & $\begin{array}{c}\text { Specificity } \\
(\%)\end{array}$ \\
\hline $\begin{array}{l}\text { Barbot, et al. } 2016 \text { [17] (oCRH or } \\
\text { hCRH) }\end{array}$ & 170 (149 CD, $21 \mathrm{EAS})$ & & & & 72.4 & 76 & 100 \\
\hline Reimondo, et al. 2003 [19] (oCRH) & 59 (49 CD, 10 EAS) & 30 & 61 & 70 & 50 & 86 & 90 \\
\hline Vilar, et al. 2008 [20] (oCRH) & 19 (16 CD, 3 EAS) & $\begin{array}{l}20 \\
50\end{array}$ & $\begin{array}{l}81.2 \\
62.5\end{array}$ & $\begin{array}{l}66.7 \\
66.7\end{array}$ & $\begin{array}{l}35 \\
50\end{array}$ & $\begin{array}{l}93.5 \\
81.2\end{array}$ & $\begin{array}{l}100 \\
100\end{array}$ \\
\hline Suda, et al. 2009 [21] (hCRH) & 123 (96 CD, 27 EAS) & & & & 50 & 96 & 73.3 \\
\hline Ritzel, et al. 2015 [22] (hCRH) & 96 (78 CD, 18 EAS) & 30 & 78 & 78 & $\begin{array}{c}50 \\
43 \text { at } 15 \mathrm{~min}\end{array}$ & $\begin{array}{l}83 \\
83\end{array}$ & $\begin{array}{l}89 \\
94\end{array}$ \\
\hline Frete, et al. 2020 [23] (hCRH) & 194 (167 CD, 27 EAS) & 17 & 90.4 & 85.2 & 37 & 88 & 81.5 \\
\hline Ceccato, et al. 2020 [24] (hCRH) & 101 (86 CD, 15 EAS) & 20 & 85.9 & 80 & 31 & 90.7 & 80 \\
\hline Newell-Price, et al. 2002 [67] (hCRH) & 115 (101 CD, 14 EAS) & 14 & 85 & 100 & & & \\
\hline
\end{tabular}

Abbreviations: ACTH, adrenocorticotropin hormone; oCRH, ovine corticotropin-releasing hormone; $\mathrm{hCRH}$, human corticotropin-releasing hormone; $\mathrm{CD}$ Cushing's disease; EAS, ectopic ACTH secretion. 
best predictor of a pituitary origin was an ACTH increase $>72.4 \%$ above the baseline, resulting in $76 \%$ sensitivity and $100 \%$ specificity [17]. According to a recent study by Frete, et al. [23], the criteria associated with the best compromise between sensitivity and specificity were a relative cortisol increase $>17 \%$ and ACTH increase $>37 \%$, with $83 \%$ sensitivity and $85 \%$ specificity. Based on our 10-year experience of using human $\mathrm{CRH}$, we also recently reported that a cortisol increase of $>20 \%$ or an $\mathrm{ACTH}$ increase of $>31 \%$ resulted in $91 \%-86 \%$ sensitivity and $80 \%$ specificity to diagnose CD, as shown in Table 1 [24].

\section{HIGH-DOSE DEXAMETHASONE SUPPRESSION TEST (HDDST)}

The HDDST can help distinguish CD from EAS because high doses of glucocorticoids partially suppress ACTH secretion from most corticotroph adenomas, which retain some responsiveness to negative feedback, whereas ectopic neuroendocrine tumors are resistant to feedback inhibition [25]. However, some welldifferentiated neuroendocrine neoplasms (in particular bronchial, thymic, and pancreatic carcinoids) can be sensitive to the feedback inhibition of ACTH. Plasma and/or urinary cortisol levels are therefore evaluated before and after dexamethasone administration [6].

The most common schedule for the HDDST is $8 \mathrm{mg}$ overnight: specifically, the patient takes $8 \mathrm{mg}$ of oral dexamethasone at
11:00 p.m. and the plasma cortisol collection occurs at 8:00 a.m. the next morning. Another version of the HDDST consists of administration of $2 \mathrm{mg}$ dexamethasone every 6 hours (for a total of eight doses), and plasma cortisol collection also occurs at 8:00 a.m. the next morning.

The sensitivity and specificity of the HDDST depend on the cut-off considered (Table 2). Vilar, et al. [20] found that a decrease in serum cortisol below $50 \%$ is suggestive of $C D$, achieving $71.4 \%$ specificity, which could be further improved to $100 \%$ using a cortisol suppression cut-off of $80 \%$. Ritzel, et al. [22] found the highest positive likelihood ratio with a cut-off value of $71 \%$ suppression of basal cortisol. In our case series, a cut-off value of $52.7 \%$ for cortisol suppression showed the best performance in diagnosing CD [17]. Other studies confirmed a high diagnostic accuracy adopting a serum cortisol threshold of 50\% suppression after the HDDST, as shown in Table 2 [19, 21, 22, 26-28].

Vilar, et al. [20] observed a gain in diagnostic accuracy when matching the results of different dynamic tests: the combination of an $\mathrm{ACTH}$ response to $\mathrm{CRH}$ or desmopressin (deamino D-arginine vasopressin, DDAVP, $\geq 35 \%$ above basal) and cortisol suppression $>50 \%$ after the HDDST was found only in patients with CD, with $63.3 \%$ sensitivity and $100 \%$ specificity. Similar results were described in our case series, in which none of the patients with EAS showed a positive result in both the HDDST and $\mathrm{CRH}$ test [17].

The potential pitfalls of the HDDST are cyclical CS, in which

Table 2. Diagnostic accuracy of serum or urinary cortisol after high-dose dexamethasone administration

\begin{tabular}{lcccc}
\hline Reference & \multicolumn{1}{c}{ N patients } & Cortisol suppression (\%) & Sensitivity (\%) & Specificity (\%) \\
\hline Barbot, et al. 2016 [17] & 170 (149 CD, 21 EAS) overnight & 52.7 & 88 & 90 \\
Reimondo, et al. 2003 [19] & 59 (49 CD, 10 EAS) overnight & 50 & 77 & 60 \\
Vilar, et al. 2008 [20] & 46 (39 CD, 7 EAS) overnight & 50 & 79.5 & 71.4 \\
& & 80 & 56.4 & 100 \\
Suda, et al. 2009 [21] & 88 (73 CD, 15 EAS) overnight & 50 & 82 & 80 \\
Ritzel, et al. 2015 [22] & 96 (78 CD, 18 EAS) overnight & 50 & 86 & 71 \\
& & 71 & 64 & 93 \\
Liu, et al. 2020 [25] & 118 (102 CD, 16 EAS) 2-day & $50 \%$ (UFC) & 84 & 62.5 \\
Aron, et al. 1997 [26] & 73 (58 CD, 15 EAS) (34 overnight*, 39 2-day') & 50 & 81 & 66.7 \\
Lin, et al. 2007 [27] & 16 CD 2-day & 50 & 69 & \\
Aytug, et al. 2012 [28] & 77 CD: 8-mg overnight & 50 & 95 & \\
& 64 CD: 2-day & 80 & 62 & \\
\hline
\end{tabular}

${ }^{*}$ Overnight indicates administration of $8 \mathrm{mg}$ dexamethasone once; ${ }^{\dagger}$ 2-day indicates administration of $2 \mathrm{mg}$ of dexamethasone every 6 hours. Abbreviations: CD, Cushing's disease; EAS, ectopic adrenocorticotropin hormone secretion; UFC, urinary free cortisol. 
cortisol levels can vary during the day of the test, or the variable absorption and metabolism of dexamethasone. Some medications, including antidepressants, antihypertensives, and lipidlowering agents, can interfere with the CYP3A4 enzyme system, which regulates dexamethasone metabolism, thereby affecting the plasma dexamethasone level [1, 29]. Serum dexamethasone measurement may provide further insights; however, thresholds are not available for the HDDST [30].

\section{BILATERAL INFERIOR PETROSAL SINUS SAMPLING (BIPSS)}

BIPSS is a minimally invasive procedure that should be considered in patients with ACTH-dependent CS whose biochemical or radiological tests are discordant or non-conclusive [6, 31].

The aim of BIPSS is to compare the level of ACTH in the inferior petrosal sinuses (IPSs), which receive the blood directly from the pituitary gland, which is then transported to the peripheral vessels [32]. Blood samples for ACTH measurement are obtained simultaneously from the IPS and peripheral vein at baseline, and at 3, 5, and 10 minutes after $\mathrm{CRH}$ administration. The basal ACTH gradient between the central and peripheral samples is not always diagnostic because of intermittent ACTH secretion; therefore, stimulation of ACTH secretion with $\mathrm{CRH}$ improves the diagnostic sensitivity of this test. A central to peripheral (IPS:P) $\mathrm{ACTH}$ ratio $>2$ in the basal state and/or $>3$ after $\mathrm{CRH}$ administration is consistent with $\mathrm{CD}$ diagnosis [6].
BIPSS sensitivity at baseline ranges from $85 \%$ to $96.4 \%$ and that after $\mathrm{CRH}$ stimulation ranges from $88 \%$ to $97 \%$ in various studies, with high specificity [20, 27, 32-38]. The rate of false negatives depends on cases of corticotroph adenomas with poor responsiveness to $\mathrm{CRH}$, cyclic $\mathrm{CS}$, or anomalous venous drainage $[6,39]$.

A gradient $>1.4$ between the two sides of the pituitary has been used as a predictor of tumor localization; however, the usefulness of BIPSS for localizing the pituitary adenoma is limited, with an accuracy between 48\% and 70\% (Table 3) [16, 27, 32, $34,40]$.

Notably, BIPSS can potentially lead to adverse events due to its invasive nature. The most common minor complication is hematoma at the point of vascular access; however, serious adverse effects, including deep venous thrombosis, pulmonary embolism, and brain injury, are rare [6, 41].

DDAVP administration is an interesting alternative to $\mathrm{CRH}$ during BIPSS. Although the procedure is the same, DDAVP is less expensive and is characterized by a diagnostic accuracy comparable to that reported for $\mathrm{CRH}$ in some studies [40, 42, 43]. Recently, Chen, et al. [44] reported $87.2 \%$ baseline sensitivity, which increased to $96.5 \%$ after stimulation with DDAVP, with 100\% specificity. The optimal cut-off value of IPS:P was 1.4 before stimulation and 2.8 after stimulation with DDAVP. This cut-off showed $94.7 \%$ baseline sensitivity, $97.8 \%$ sensitivity after stimulation, and $100 \%$ specificity. Nonetheless, DDAVP is a hemostatic agent, and patients with CS are at an increased risk

Table 3. Diagnostic accuracy of BIPSS with $\mathrm{CRH}$ stimulation unless specified

\begin{tabular}{|c|c|c|c|c|c|}
\hline \multirow{2}{*}{ Reference } & \multirow{2}{*}{$\begin{array}{l}\text { Successful BIPSS } \\
\text { (N patients) }\end{array}$} & \multicolumn{2}{|c|}{ Basal IPS:P ratio $\geq 2$} & \multicolumn{2}{|c|}{ CRH or desmopressin IPS:P ratio $\geq 3$} \\
\hline & & Sensitivity (\%) & Specificity (\%) & Sensitivity (\%) & Specificity (\%) \\
\hline Vilar, et al. 2008 [20] & 13 (10 CD, 3 EAS) (4 CRH, 9 DDAVP) & 90 & 100 & 90 & 100 \\
\hline Lin, et al. 2007 [27] & $18 \mathrm{CD}$ & 89 & & 94 & \\
\hline Colao, et al. 2001 [32] & 84 (74 CD, 10 EAS) & 85 & 90 & 88 (78 patients) & 100 \\
\hline Deipolyi, et al. 2017 [33] & 248 (182 CD, 17 EAS) (CRH or DDAVP) & 89-94 (248 patients) & & 96 (222 patients) & \\
\hline Bonelli, et al. 2000 [34] & 63 (54 CD, 9 EAS) & 92.2 & 100 & 92.2 & 90 \\
\hline Wind, et al. 2013 [35] & $501 \mathrm{CD}$ & 93 & & 97 & \\
\hline Pereira, et al. 2019 [36] & 30 (28 CD, 2 EAS) & 96.4 & 100 & 96.4 & 100 \\
\hline Swearingen, et al. 2004 [37] & 145 (117 CD, 8 EAS) & 85 & 67 & 90 (95 BIPSS) & 67 \\
\hline Shi, et al. 2011 [38] & 69 (64 CD, 5 EAS) & 89.1 & 100 & & \\
\hline Chen, et al. 2020 [44] & 250 (226 CD, 24 EAS) (DDAVP) & 87.2 & 100 & 96.5 & 100 \\
\hline Grant, et al. 2012 [68] & 83 (72 CD, 10 EAS) & & & 92 & 91 \\
\hline Sheth, et al. 2012 [69] & 237 (205 CD, 10 EAS) & & & 94 & 50 \\
\hline
\end{tabular}

Abbreviations: BIPSS, bilateral inferior petrosal sinus sampling; CD, Cushing's disease; EAS, ectopic adrenocorticotropin hormone secretion; IPS:P ratio, inferior petrosal sinus to peripheral ratio; $\mathrm{CRH}$, corticotropin-releasing hormone; DDAVP, desmopressin. 
for thromboembolic events; therefore, its use during BIPSS requires extreme caution $[45,46]$.

\section{DDAVP TEST}

Other tests have been proposed to detect the origin of corticotropin in ACTH-dependent CS. DDAVP is a synthetic analog of the endogenous neuropeptide arginine-vasopressin (AVP), which binds to vasopressin receptors (VRs) with high affinity and stimulates ACTH secretion in most CD patients because of the upregulation of VR type 3 expression or aberrant expression of VR type 2 in pituitary ACTH-secreting adenomas [47, 48].

The DDAVP test is performed by the intravenous administration of $10 \mu \mathrm{g}$ of DDAVP, followed by blood sampling for plasma cortisol and ACTH measurement at -15, 0, 15, 30, 45, 60, 90, and 120 minutes (as used for $\mathrm{CRH}$ administration). $\mathrm{A}>50 \%$ increment of ACTH and $>20 \%$ increment of cortisol above baseline levels are considered to provide a positive result [47]. However, the role of DDAVP in the differential diagnosis between CD and EAS remains uncertain, as summarized in Table 4. Several types of ectopic ACTH-secreting tumors respond to DDAVP, thereby limiting the utility of this test in distinguishing the source of excess ACTH [6].

Vilar, et al. [20] found no difference in the sensitivity and specificity of both ACTH and cortisol criteria after the administration of $\mathrm{CRH}$ or DDAVP. By contrast, other studies indicated that the DDAVP test has lower specificity (40\%-81\%) than the HDDST and $\mathrm{CRH}$ test [17, 21, 23, 49, 50].

However, the DDAVP test might be useful in the post-opera- tive assessment of $\mathrm{CD}$. If the response to DDAVP in a $\mathrm{CD}$ patient is ascertained and positive before pituitary surgery, its maintenance or disappearance after surgery may be related to the persistence or complete removal of adenomatous corticotrophs, respectively. Therefore, this test can be useful as an early marker of recurrence during follow-up [51, 52].

\section{CORTISOL TO CORTISONE RATIO}

In 1996, impaired peripheral cortisol metabolism was first described as a characteristic of patients with EAS. An increased urinary free cortisol:cortisone ratio (FEr) suggests substrate saturation of renal $11 \beta$-hydroxysteroid dehydrogenase (11 $\beta$-HSD) type 2, explaining the mineralocorticoid effect of cortisol, similar to that observed in the case of apparent mineralocorticoid excess, which is a rare autosomal recessive monogenic form of hypertension [23, 54]. Cortisol is the biologically active form of glucocorticoid, which is mainly regulated by $11 \beta-H S D$ isoenzymes and the glucocorticoid receptor. The kidneys receive 20\%-25\% of the cardiac output, and plasma free cortisol levels are 100fold higher than those of aldosterone, providing a large amount of cortisol in the main mineralocorticoid-sensitive organs. Moreover, cortisol has higher affinity than aldosterone for mineralocorticoid receptor [55]. 11ß-HSD1 is a bidirectional enzyme with both reductase and dehydrogenase activity; the former is predominant in the liver, lung, brain, adipose tissue, bone, and muscle. $11 \beta-H S D 2$ is a dehydrogenase that inactivates cortisol to cortisone, which is predominantly expressed in mineralocorticoid-sensitive organs such as the kidneys (distal nephron) and

Table 4. Diagnostic accuracy of the desmopressin test

\begin{tabular}{|c|c|c|c|c|c|c|c|}
\hline Reference & $\mathrm{N}$ patients & $\begin{array}{c}\text { Cortisol rise } \\
\text { (\% above basal) }\end{array}$ & $\begin{array}{l}\text { Sensitivity } \\
(\%)\end{array}$ & $\begin{array}{l}\text { Specificity } \\
\text { (\%) }\end{array}$ & $\begin{array}{c}\text { ACTH rise } \\
\text { (\% above basal) }\end{array}$ & $\begin{array}{c}\text { Sensitivity } \\
(\%)\end{array}$ & $\begin{array}{l}\text { Specificity } \\
(\%)\end{array}$ \\
\hline Barbot, et al. 2016 [17] & 170 (149 CD, 21 EAS) & & & & 32 & 83 & 62 \\
\hline \multirow[t]{2}{*}{ Vilar, et al. 2008 [20] } & 25 (21 CD, 4 EAS) & 20 & 76.2 & 75 & 35 & 85.7 & 75 \\
\hline & & 50 & 47.6 & 75 & 50 & 76.2 & 100 \\
\hline Suda, et al. 2009 [21] & 31 (22 CD, 9 EAS) & & & & 50 & 86 & 55.6 \\
\hline Frete, et al. 2020 [23] & 194 (167 CD, 27 EAS) & 18 & 89.8 & 70.4 & 33 & 85.5 & 77.8 \\
\hline \multirow[t]{2}{*}{ Terzolo, et al. 2001 [49] } & 24 (19 CD, 5 EAS) & & & & 35 & 89 & 40 \\
\hline & & & & & 50 & 84 & 40 \\
\hline Tsagarakis, et al. 2002 [50] & 31 (26 CD, 5 EAS) & 20 & 73 (19/26 CD) & 40 (3/5 EAS) & 50 & 81 (21/26 CD) & 40 (3/5 EAS) \\
\hline Sakai, et al. 1997 [70] & 13 (10 CD, 3 EAS) & & & & 150 & 100 (10/10 CD) & 100 (0/3 EAS) \\
\hline Newell-Price, et al. 1997 [71] & 23 (17 CD, 5 EAS) & 20 & 82 (14/17 CD) & 80 (1/5 EAS) & 35 & 71 (12/17 CD) & 40 (3/5 EAS) \\
\hline Colombo, et al. 1997 [72] & 18 (17 CD, 1 EAS) & 20 & 82 (14/17 CD) & $100(0 / 1)$ & 50 & 82 (14/17 CD) & 100 (0/1 EAS) \\
\hline
\end{tabular}

Abbreviations: CD, Cushing's disease; EAS, ectopic adrenocorticotropin hormone secretion. 
salivary glands [54]. Therefore, 11ß-HSD2 enables aldosterone to activate mineralocorticoid receptor, in turn inactivating cortisol to cortisone. Chromatography and mass spectrometry-based methods are increasingly being used in routine clinical chemistry, enabling improved diagnosis of cortisol excess and the measurement of cortisone $[56,57]$. In 2017, in a large series of patients with ACTH-dependent CS (83 with CD and 24 with EAS), we reported that the diagnostic accuracy of FEr $>1.15$ was similar to that of the $\mathrm{CRH}$ test or HDDST, especially in patients with discordant test results [58]. Further and larger studies, including prospective ones, are needed to assess the exact role of FEr in the diagnostic flow chart of ACTH-dependent CS.

\section{CONVENTIONAL AND NUCLEAR IMAGING IN ACTH-DEPENDENT CS}

Despite its high specificity (up to $96 \%$ in a recent large series), pituitary MRI cannot be completely relied upon to differentiate the origin of ACTH hypersecretion (a pituitary or ectopic origin) [59]. Although evidence of a $>6$-mm pituitary adenoma in the diagnostic work-up for ACTH-dependent hypercortisolism is highly suggestive of a pituitary source of ACTH secretion, this is not the case for small lesions that might be incidentalomas (in 5 out of 26 patients with EAS), and might represent a false-positive MRI finding in the context of an occult EAS with discordant dynamic test results [59].

Accurate interpretation of conventional imaging (abdominal and chest computed tomography [CT], pituitary MRI) could be useful to reduce the numbers of BIPSS in patients with discordant results between second-line screening tests for ACTH-dependent CS (i.e., CRH and DDAVP tests). In a large French cohort of 194 patients with ACTH-dependent CS, BIPSS could be avoided in $50 \%$ of cases by combining positive and concordant responses to dynamic tests ( $\mathrm{CRH}$ and desmopressin) with imaging findings [23].

Localization of the EAS source is crucial because early localization and treatment can avoid unnecessary adrenalectomy and reduce the risk of progression through metastatic disease. Once EAS is suspected (notably not confirmed, because imaging is independent of cortisol levels), high-resolution conventional imaging is the preferred technique, as it is the best approach to localize the source of ectopic ACTH secretion (98\% sensitivity for CT and 93\% for MRI in EAS) [12].

By definition, an occult EAS is not detected during the initial management of hypercortisolism. Isidori, et al. [12] reported that in $30 \%$ of cases, the ACTH source was detected during fol- low-up. Nuclear medicine improves the sensitivity of conventional radiology when tumor site identification is a challenge: in patients with negative CT and MRI findings, a positive finding of octreoscan was described in 67\% of cases (50 patients), and $60 \%$ (32 patients) were ${ }^{18}$ fluorodeoxyglucose positron emission tomography (PET)-positive; thus, almost $75 \%$ of cases with initial occult EAS (as determined using conventional imaging) were successfully diagnosed using nuclear imaging [12].

$\mathrm{PET} / \mathrm{CT}$ using ${ }^{68} \mathrm{Ga}$-conjugated somatostatin receptor-targeting peptide ( ${ }^{68} \mathrm{Ga}-\mathrm{SSTR}$-PET/CT) shows high sensitivity. In 2016, Goroshi, et al. [60] compared the diagnostic accuracy of conventional (contrast-enhanced CT) and nuclear ( ${ }^{68} \mathrm{Ga}-\mathrm{SSTR}$-PET/ CT) imaging in a small series of 12 patients. CT detected $90 \%$ of neuroendocrine tumors in overt EAS, whereas ${ }^{68} \mathrm{Ga}-\mathrm{SSTR}$ PET/CT identified $70 \%$ of cases, without false-positive imaging results, demonstrating its utility to increase the specificity of the suggestive CT-positive lesions. In this series, the only EAS not detected with conventional imaging remained occult after ${ }^{68} \mathrm{Ga}$ SSTR-PET/CT. In a recent multicenter study, Wannachalee, et al. [61] reported that ${ }^{68} \mathrm{Ga}-\mathrm{SSTR}$-PET/CT is sensitive to detecting primary and metastatic neoplasms in EAS (28 cases), and to identify occult tumors, achieving a significant clinical impact in diagnostic and therapeutic management for $65 \%$ of patients. However, we recently reported that ${ }^{68} \mathrm{Ga}$-SSTR-PET/CT presents a considerable number of indeterminate/false-positive images, thus requiring careful interpretation [62].

\section{CASE PRESENTATION}

A 27-year-old male was referred to the Endocrine Unit of the University-Hospital of Padova, Padova, Italy, in 2017 after developing truncal obesity, facial rounding, and plethora in the previous four to six months. There were no medical events or endocrine diseases in his own or familial medical history. Informed consent was obtained from the patient for publication of this case.

Physical examination revealed a plethoric moon-shaped face and central obesity, without purple striae or a buffalo hump. The blood pressure was 150/90 mm Hg, and the patient's height, body weight, and waist circumference were $187 \mathrm{~cm}, 90 \mathrm{~kg}$, and $104 \mathrm{~cm}$, respectively (body mass index $25.74 \mathrm{~kg} / \mathrm{m}^{2}$ ).

The results of routine laboratory tests including liver and kidney function tests were normal. The fasting plasma glucose level of $6.5 \mathrm{mmol} / \mathrm{L}$ [reference interval (RI): $3.7-5.6 \mathrm{mmol} / \mathrm{L}$ ] and glycosylated hemoglobin level of $44 \mathrm{mmol} / \mathrm{mol}$ (RI: $20-42 \mathrm{mmol} /$ $\mathrm{mol}$ ) were consistent with new-onset impaired fasting glucose. A sodium level of $146 \mathrm{mmol} / \mathrm{L}$ (RI: 136-145 mmol/L) and potas- 
sium level of $3.5 \mathrm{mmol} / \mathrm{L}$ (RI: $3.4-4.5 \mathrm{mmol} / \mathrm{L}$ ) suggested increased mineralocorticoid activity.

After exclusion of exogenous steroids, first-line screening tests for suspected endogenous hypercortisolism were performed. The 24 hours urinary free cortisol excretion level was elevated (6.465-5.375 nmol/24 hours; RI: 16-168 nmol/24 hours), the salivary cortisol rhythm was impaired (late-night salivary cortisol level of 55-46 nmol/L; RI: 0.5-2.6 nmol/L), and serum cortisol level was not suppressed after administration of $1 \mathrm{mg}$ dexamethasone (cortisol $444 \mathrm{nmol} / \mathrm{L}$ ). These results confirmed a diagnosis of endogenous CS. ACTH levels were increased (14.1 pmol/ L; RI: 2.2-11 pmol/L), indicating ACTH-dependent CS.

Over the next few weeks, hypokalemia was observed along with increased blood pressure levels. Therefore, we initiated medical therapy with potassium canrenoate and metyrapone, which achieved rapid control of blood pressure and potassium levels.

To identify the source of ACTH secretion, the patient underwent all second-line dynamic tests for ACTH-dependent hypercortisolism.

After the human $\mathrm{CRH}$ test $(100 \mu \mathrm{g})$, there was a significant increase in both ACTH level (15.2 to $50.6 \mathrm{pmol} / \mathrm{L},+233.3 \%$ ) and cortisol level (763 to $1.631 \mathrm{nmol} / \mathrm{L},+113.8 \%$ ). There was also a significant increase in both ACTH level (16.8 to $27.7 \mathrm{pg} /$ $\mathrm{mL},+64.7 \%$ ) and cortisol level (778 to $1,032 \mathrm{nmol} / \mathrm{L},+32 \%$ ) during the DDAVP test. These results suggested pituitary ACTH secretion (Fig. 1). However, no cortisol suppression was found
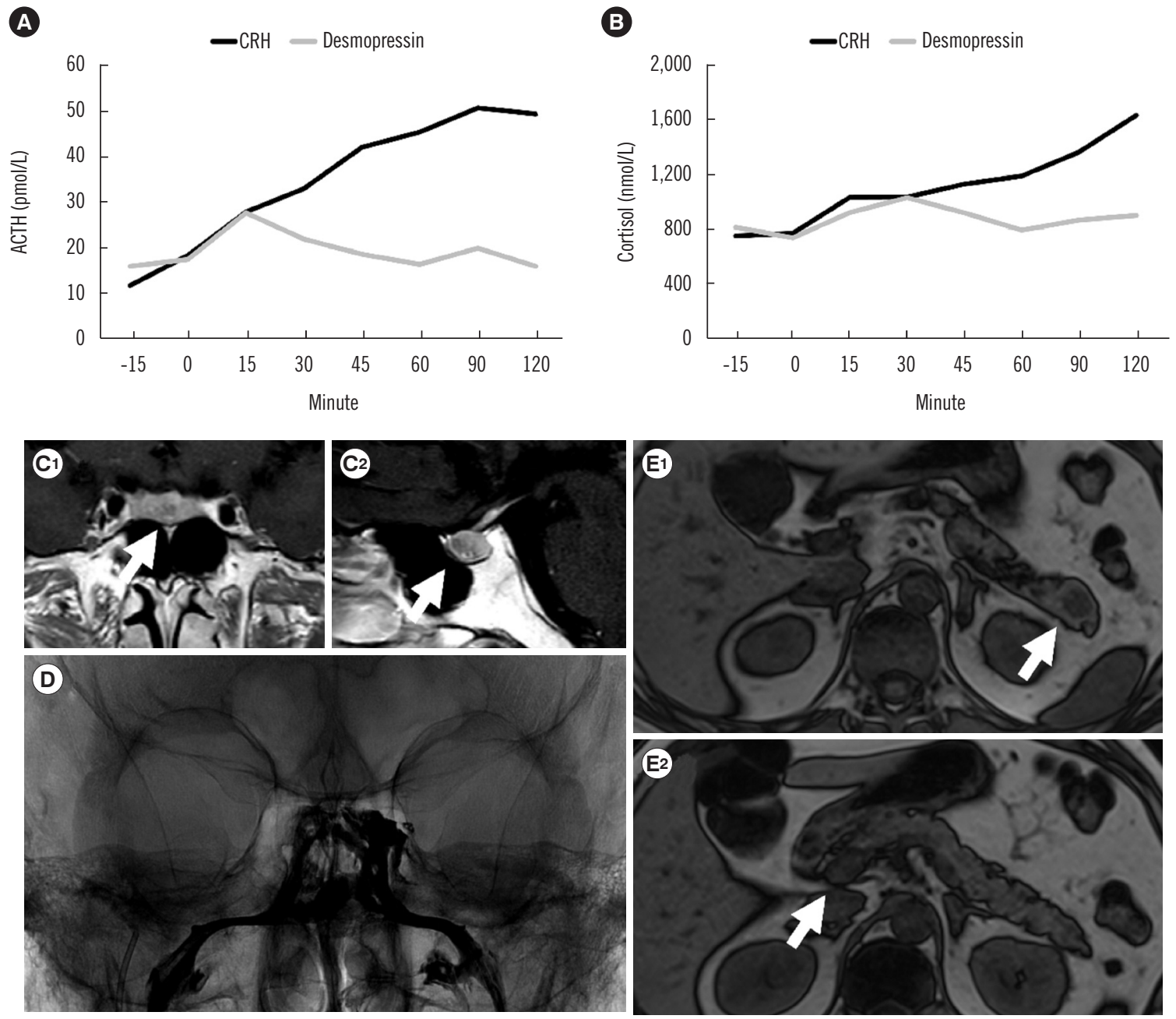

Fig. 1. Dynamic tests and radiological features of the case presented in the text. (A) ACTH and (B) cortisol response to the CRH test (black) and desmopressin test (gray). (C-E) Magnetic resonance images showing the hypo-intense anterior-median pituitary adenoma (white arrows) in the coronal (C1) and sagittal (C2) planes; enhanced image during bilateral inferior petrosal sinus sampling (D); and the pancreatic tail (E1) and head (E2) nodules in the axial plane (white arrows).

Abbreviations: $\mathrm{ACTH}$, adrenocorticotropin hormone; $\mathrm{CRH}$, corticotropin-releasing hormone. 
after the HDDST (8 mg overnight, cortisol level 778 to $690 \mathrm{nmol} / \mathrm{L}$, $-11.3 \%)$.

Pituitary MRI revealed a 4-mm pituitary microadenoma; however, the clinical features, in particular the rapid onset of severe hypertension and hypokalemia, combined with reduced cortisol suppression after the HDDST, suggested EAS. Therefore, the patient underwent chest CT and abdominal enhanced MRI, which showed multiple pancreatic nodules; their neuroendocrine origin was suggested by the uptake of 68-Ga-DOTATOC PET/CT, confirming the presence of somatostatin receptors.

Considering the discordant responses to second-line dynamic tests and evidence of both pituitary and pancreatic lesions, we decided to perform BIPSS to facilitate the differential diagnosis between CD and EAS. The central IPS to peripheral (P) ACTH ratio (IPS:P =25) after $\mathrm{CRH}$ administration confirmed the pituitary origin of $\mathrm{ACTH}$ secretion.

Based on the clinical presentation (pituitary adenoma and pancreatic nodules in a young patient), we performed Sanger sequencing for multiple endocrine neoplasia type 1 (MEN1), which confirmed a pathogenic variant in the menin gene (base pair in- sertions c.188_189TT cDNA692_693_inTT Q64Sfs56, loss of frameshift).

The patient underwent pituitary surgery, and histological examination confirmed a pituitary adenoma with positive ACTH staining. After surgery, low levels of morning serum cortisol confirmed the remission of $\mathrm{CD}$, requiring replacement therapy. On physical examination, we observed reduction in body weight and facial plethora; moreover, the patient's blood pressure normalized without antihypertensive treatment.

A few months after the pituitary surgery, the patient underwent abdominal surgery (duodeno-cephalo-pancreatectomy and distal pancreatectomy). The histology report revealed well-differentiated neuroendocrine tumors and focal nesidioblastosis; immunohistochemistry showed positive staining for chromogranin, synaptophysin, and glucagon, and negative staining for ACTH, serotonin, somatostatin, gastrin, insulin, and pancreatic polypeptide.

At the last follow-up visit (38 months since diagnosis), clinical and biochemical parameters confirmed remission of $\mathrm{CD}$, and abdominal imaging markers of neuroendocrine neoplasia were also negative.

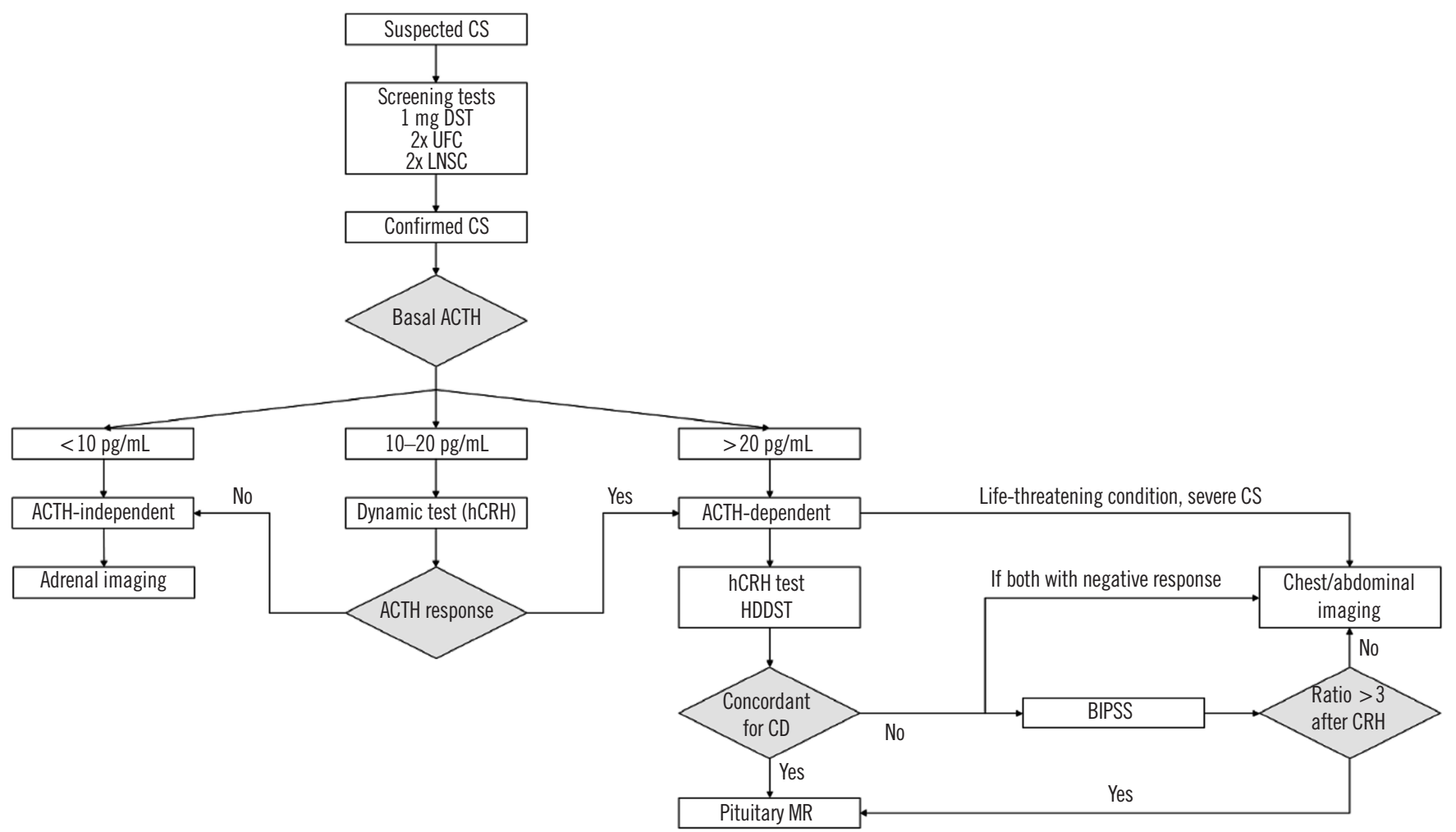

Fig. 2. Proposed flow chart for the diagnosis of CS. In selected cases, BIPSS could be avoided if MRI shows a pituitary adenoma $\geq 6$ mm. Abbreviations: CS, Cushing's syndrome; DST, dexamethasone suppression test; UFC, urinary free cortisol; LNSC, late-night salivary cortisol; hCRH, human corticotropin-releasing hormone; ACTH, adrenocorticotropin hormone; HDDST, high-dose dexamethasone suppression test; CD, Cushing's disease; MR, magnetic resonance; BIPSS, bilateral inferior petrosal sinus sampling. 


\section{CONCLUSIONS AND FUTURE PERSPECTIVE}

Endocrinologists who are skilled in making a CS diagnosis and have the necessary multidisciplinary expertise are usually found only at referral or academic medical centers.

In 2017, a simplified flow chart for CS diagnosis was proposed, which focused on the measurement of basal ACTH level, imaging, and BIPSS [63]. However, several authors have questioned this suggestion [64-66].

In our opinion, a step-by-step approach could be used in patients with ACTH-dependent hypercortisolism for making a differential diagnosis, as detailed in Fig. 2. Nonetheless, this flow chart is only based upon our expertise, which should be evaluated in a large multicenter cohort. In the era of precision medicine, a novel approach, ideally a patient-centered one, should be proposed in the differential diagnosis of ACTH-dependent CS.

\section{ACKNOWLEDGEMENTS}

None.

\section{AUTHOR CONTRIBUTIONS}

Pinelli S: writing original draft, literature review; Barbot M: writing and editing; Scaroni C: supervision, validation; Ceccato F: writing original draft, literature review, manuscript submission. All authors contributed equally to the literature review and manuscript preparation. They all approved the final version of the paper.

\section{CONFLICTS OF INTEREST}

None of the authors has any conflicts of interest to disclose that might be perceived as influencing the impartiality of the reported research.

\section{RESEARCH FUNDING}

None declared.

\section{ORCID}

Silvia Pinelli
Mattia Barbot
Carla Scaroni
Filippo Ceccato https://orcid.org/0000-0002-1944-7182 https://orcid.org/0000-0002-1081-5727 https://orcid.org/0000-0001-9396-3815 https://orcid.org/0000-0003-1456-8716

\section{REFERENCES}

1. Nieman LK, Biller BM, Findling JW, Newell-Price J, Savage MO, Stewart PM, et al. The diagnosis of Cushing's syndrome: an Endocrine Society clinical practice guideline. J Clin Endocrinol Metab 2008;93:1526-40.

2. Ceccato F and Boscaro M. Cushing's syndrome: screening and diagnosis. High Blood Press Cardiovasc Prev 2016;23:209-15.

3. Boscaro M and Arnaldi G. Approach to the patient with possible Cushing's syndrome. J Clin Endocrinol Metab 2009;94:3121-31.

4. Shimon I. Screening for Cushing's syndrome: is it worthwhile? Pituitary 2015; 18:201-5.

5. Ceccato F, Marcelli G, Martino M, Concettoni C, Brugia M, Trementino L, et al. The diagnostic accuracy of increased late night salivary cortisol for Cushing's syndrome: a real-life prospective study. J Endocrinol Invest 2019;42:327-35.

6. Arnaldi G, Angeli A, Atkinson AB, Bertagna X, Cavagnini F, Chrousos $\mathrm{GP}$, et al. Diagnosis and complications of Cushing's syndrome: a consensus statement. J Clin Endocrinol Metab 2003;88:5593-602.

7. Nieman LK, Biller BM, Findling JW, Murad MH, Newell-Price J, Savage $\mathrm{MO}$, et al. Treatment of Cushing's syndrome: an Endocrine Society clinical practice guideline. J Clin Endocrinol Metab 2015;100:2807-31.

8. Lacroix A, Feelders RA, Stratakis CA, Nieman LK. Cushing's syndrome. Lancet 2015;386:913-27.

9. Barbot M, Zilio M, Scaroni C. Cushing's syndrome: overview of clinical presentation, diagnostic tools and complications. Best Pract Res Clin Endocrinol Metab 2020;34:101380.

10. Pecori Giraldi F, Saccani A, Cavagnini F; Study Group on the Hypothalamo-Pituitary-Adrenal Axis of the Italian Society of Endocrinology. Assessment of ACTH assay variability: a multicenter study. Eur J Endocrinol 2011;164:505-12.

11. Hernández I, Espinosa-de-los-Monteros AL, Mendoza V, Cheng S, Molina M, Sosa E, et al. Ectopic ACTH-secreting syndrome: a single center experience report with a high prevalence of occult tumor. Arch Med Res 2006;37:976-80.

12. Isidori AM, Sbardella E, Zatelli MC, Boschetti M, Vitale G, Colao A, et al. Conventional and nuclear medicine imaging in ectopic Cushing's syndrome: a systematic review. J Clin Endocrinol Metab 2015;100:323144.

13. Barbot M, Albiger N, Koutroumpi S, Ceccato F, Frigo AC, Manara R, et al. Predicting late recurrence in surgically treated patients with Cushing's disease. Clin Endocrinol 2013;79:394-401.

14. Testa RM, Albiger N, Occhi G, Sanguin F, Scanarini M, Berlucchi S, et al. The usefulness of combined biochemical tests in the diagnosis of Cushing's disease with negative pituitary magnetic resonance imaging. Eur J Endocrinol 2007;156:241-8.

15. Lonser RR, Nieman L, Oldfield EH. Cushing's disease: pathobiology, diagnosis, and management. J Neurosurg 2017;126:404-17.

16. Kola B and Grossman AB. Dynamic testing in Cushing's syndrome. Pituitary 2008;11:155-62.

17. Barbot M, Trementino L, Zilio M, Ceccato F, Albiger N, Daniele A, et al. Second-line tests in the differential diagnosis of ACTH-dependent Cushing's syndrome. Pituitary 2016;19:488-95.

18. Pecori Giraldi F, Invitti C, Cavagnini F, Study Group of the Italian Society of Endocrinology on the pathophysiology of the hypothalamic-pituitaryadrenal axis. The corticotropin-releasing hormone test in the diagnosis of ACTH-dependent Cushing's syndrome: a reappraisal. Clin Endocrinol (Oxf) 2001;54:601-7.

19. Reimondo G, Paccotti P, Minetto M, Termine A, Stura G, Bergui M, et al. The corticotrophin-releasing hormone test is the most reliable nonin- 
vasive method to differentiate pituitary from ectopic ACTH secretion in Cushing's syndrome. Clin Endocrinol 2003;58:718-24.

20. Vilar L, Freitas MC, Naves LA, Canadas V, Albuquerque JL, Botelho CA, et al. The role of non-invasive dynamic tests in the diagnosis of Cushing's syndrome. J Endocrinol Invest 2008;31:1008-13.

21. Suda T, Kageyama K, Nigawara T, Sakihara S. Evaluation of diagnostic tests for ACTH-dependent Cushing's syndrome. Endocr J 2009;56:46976.

22. Ritzel K, Beuschlein F, Berr C, Osswald A, Reisch N, Bidlingmaier M, et al. ACTH after 15 min distinguishes between Cushing's disease and ectopic Cushing's syndrome: a proposal for a short and simple CRH test. Eur J Endocrinol 2015;173:197-204.

23. Frete C, Corcuff JB, Kuhn E, Salenave S, Gaye D, Young J, et al. Noninvasive diagnostic strategy in ACTH-dependent Cushing's syndrome. J Clin Endocrinol Metab 2020;105:3273-84.

24. Ceccato F, Tizianel I, Vedolin CK, Boscaro M, Barbot M, Scaroni C. Human corticotropin-releasing hormone tests: 10 years of real-life experience in pituitary and adrenal disease. J Clin Endocrinol Metab 2020; 105:dgaa564.

25. Liu Z, Zhang X, Wang Z, You H, Li M, Feng F, et al. High positive predictive value of the combined pituitary dynamic enhanced MRI and highdose dexamethasone suppression tests in the diagnosis of Cushing's disease bypassing bilateral inferior petrosal sinus sampling. Sci Rep 2020; 10;14694.

26. Aron DC, Raff H, Findling JW. Effectiveness versus efficacy: the limited value in clinical practice of high dose dexamethasone suppression testing in the differential diagnosis of adrenocorticotropin-dependent Cushing's syndrome. J Clin Endocrinol Metab 1997;82:1780-5.

27. Lin LY, Teng MM, Huang Cl, Ma WY, Lin LY, Teng MM, et al. Assessment of bilateral inferior petrosal sinus sampling (BIPSS) in the diagnosis of Cushing's disease. J Chin Med Assoc 2007;70:4-10.

28. Aytug S, Laws ER Jr, Vance ML. Assessment of the utility of the highdose dexamethasone suppression test in confirming the diagnosis of Cushing disease. Endocr Pract 2012;18:152-7.

29. Albiger NME, Scaroni CM, Mantero F. Cyclic Cushing's syndrome: an overview. Arq Bras Endocrinol Metab 2007;51:1253-60.

30. Ceccato F, Artusi C, Barbot M, Lizzul L, Pinelli S, Costantini G, et al. Dexamethasone measurement during low-dose suppression test for suspected hypercortisolism: threshold development with and validation. J Endocrinol Invest 2020;43:1105-13.

31. Young J, Haissaguerre M, Viera-Pinto O, Chabre O, Baudin E, Tabarin A. Management of endocrine disease: Cushing's syndrome due to ectopic ACTH secretion: an expert operational opinion. Eur J Endocrinol 2020; 182:R29-58.

32. Colao A, Faggiano A, Pivonello R, Pecori Giraldi F, Cavagnini F, Lombardi $G$, et al. Inferior petrosal sinus sampling in the differential diagnosis of Cushing's syndrome: results of an Italian multicenter study. Eur J Endocrinol 2001;144:499-507.

33. Deipolyi A, Bailin A, Hirsch JA, Walker TG, Oklu R. Bilateral inferior petrosal sinus sampling: experience in 327 patients. J Neurointerv Surg 2017;9:196-9.

34. Bonelli FS, Huston J, Carpenter PC, Erickson D, Young WF, Meyer FB. Adrenocorticotropic hormone-dependent Cushing's syndrome: sensitivity and specificity of inferior petrosal sinus sampling. Am J Neuroradiol 2000;21:690-6.

35. Wind JJ, Lonser RR, Nieman LK, DeVroom HL, Chang R, Oldfield EH. The lateralization accuracy of inferior petrosal sinus sampling in 501 patients with Cushing's disease. J Clin Endocrinol Metab 2013;98:228593.

36. Pereira CA, Ferreira L, Amaral C, Alves V, Xavier J, Ribeiro I, et al. Diag- nostic accuracy of bilateral inferior petrosal sinus sampling: the experience of a tertiary centre. Exp Clin Endocrinol Diabetes 2019;129:12630.

37. Swearingen B, Katznelson L, Miller K, Grinspoon S, Waltman A, Dorer DJ, et al. Diagnostic errors after inferior petrosal sinus sampling. J Clin Endocrinol Metab 2004;89:3752-63.

38. Shi X, Sun Q, Bian L, Zhao W, Shen J, Wang W, et al. Assessment of bilateral inferior petrosal sinus sampling in the diagnosis and surgical treatment of the ACTH-dependent Cushing's syndrome: a comparison with other tests. Neuro Endocrinol Lett 2011;32:865-73.

39. Lefournier V, Martinie M, Vasdev A, Bessou P, Passagia JG, Labat-Moleur $F$, et al. Accuracy of bilateral inferior petrosal or cavernous sinuses sampling in predicting the lateralization of Cushing's disease pituitary microadenoma: influence of catheter position and anatomy of venous drainage. J Clin Endocrinol Metab 2003;88:196-203.

40. Deipolyi AR, Alexander B, Rho J, Hirsch JA, Oklu R. Bilateral inferior petrosal sinus sampling using desmopressin or corticotropic-releasing hormone: a single-center experience. J Neurointerv Surg 2015;7:690-3.

41. Zampetti B, Grossrubatscher E, Dalino Ciaramella P, Boccardi E, Loli P. Bilateral inferior petrosal sinus sampling. Endocr Connect 2016;5:R1225.

42. Castinetti F, Morange I, Dufour H, Jaquet P, Conte-Devolx B, Girard N, et al. Desmopressin test during petrosal sinus sampling: a valuable tool to discriminate pituitary or ectopic ACTH-dependent Cushing's syndrome. Eur J Endocrinol 2007;157:271-7.

43. Machado MC, de Sa SV, Domenice S, Fragoso MC, Puglia P Jr, Pereira MA, et al. The role of desmopressin in bilateral and simultaneous inferior petrosal sinus sampling for differential diagnosis of ACTH-dependent Cushing's syndrome. Clin Endocrinol 2007;66:136-42.

44. Chen S, Chen K, Wang S, Zhu H, Lu L, Zhang X, et al. The optimal cutoff of BIPSS in differential diagnosis of ACTH-dependent Cushing's syndrome: is stimulation necessary? J Clin Endocrinol Metab 2020;105: e1673-85.

45. Zilio M, Mazzai L, Sartori MT, Barbot M, Ceccato F, Daidone V, et al. A venous thromboembolism risk assessment model for patients with Cushing's syndrome. Endocrine 2016;52:322-32.

46. Pecori Giraldi F, Federici AB, Cavagnini F. Caution during use of desmopressin in IPSS. J Neurointerv Surg 2013;5:e27.

47. Luque RM, Ibáñez-Costa A, López-Sánchez LM, Jiménez-Reina L, Venegas-Moreno E, Gálvez MA, et al. A cellular and molecular basis for the selective desmopressin-induced ACTH release in Cushing disease patients: key role of AVPR1b receptor and potential therapeutic implications. J Clin Endocrinol Metab 2013;98:4160-9.

48. Vassiliadi DA and Tsagarakis S. Diagnosis of endocrine disease: the role of the desmopressin test in the diagnosis and follow-up of Cushing's syndrome. Eur J Endocrinol 2018;178:R201-14.

49. Terzolo M, Reimondo G, Alì A, Borretta G, Cesario F, Pia A, et al. The limited value of the desmopressin test in the diagnostic approach to Cushing's syndrome. Clin Endocrinol 2001;54:609-16.

50. Tsagarakis S, Tsigos C, Vasiliou V, Tsiotra P, Kaskarelis J, Sotiropoulou C, et al. The desmopressin and combined $\mathrm{CRH}$-desmopressin tests in the differential diagnosis of ACTH-dependent Cushing's syndrome: constraints imposed by the expression of V2 vasopressin receptors in tumors with ectopic ACTH secretion. J Clin Endocrinol Metab 2002;87:1646-53.

51. Colombo P, Dall'Asta C, Barbetta L, Re T, Passini E, Faglia G, et al. Usefulness of the desmopressin test in the postoperative evaluation of patients with Cushing's disease. Eur J Endocrinol 2000;143:227-34.

52. Ambrogio AG, Andrioli M, De Martin M, Cavagnini F, Pecori Giraldi F. Usefulness of desmopressin testing to predict relapse during long-term follow-up in patients in remission from Cushing's disease. Endocr Con- 
nect 2017;6:791-9.

53. Palermo M, Shackleton $\mathrm{CH}$, Mantero F, Stewart PM. Urinary free cortisone and the assessment of 11 beta-hydroxysteroid dehydrogenase activity in man. Clin Endocrinol 1996;45:605-11.

54. Ceccato F and Mantero F. Monogenic forms of hypertension. Endocrinol Metab Clin North Am 2019;48:795-810.

55. Funder JW. Apparent mineralocorticoid excess. J Steroid Biochem Mol Biol 2017;165:151-3.

56. Antonelli G, Ceccato F, Artusi C, Marinova M, Plebani M. Salivary cortisol and cortisone by LC-MS/MS: validation, reference intervals and diagnostic accuracy in Cushing's syndrome. Clin Chim Acta 2015;451: 247-51.

57. Casals $G$ and Hanzu FA. Cortisol measurements in Cushing's syndrome: immunoassay or mass spectrometry? Ann Lab Med 2020;40:285-96.

58. Ceccato F, Trementino L, Barbot M, Antonelli G, Plebani M, Denaro L, et al. Diagnostic accuracy of increased urinary cortisol/cortisone ratio to differentiate ACTH-dependent Cushing's syndrome. Clin Endocrinol 2017;87:500-7.

59. Yogi-Morren D, Habra MA, Faiman C, Bena J, Hatipoglu B, Kennedy L, et al. Pituitary MRI findings in patients with pituitary and ectopic ACTHdependent Cushing syndrome: does a 6-mm pituitary tumor size cut-off value exclude ectopic ACTH syndrome? Endocr Pract 2015;21:1098103.

60. Goroshi MR, Jadhav SS, Lila AR, Kasaliwal R, Khare S, Yerawar CG, et al. Comparison of 68Ga-DOTANOC PET/CT and contrast-enhanced CT in localisation of tumours in ectopic ACTH syndrome. Endocr Connect 2016;5:83-91.

61. Wannachalee T, Turcu AF, Bancos I, Habra MA, Avram AM, Chuang $\mathrm{HH}$, et al. The clinical impact of [68Ga]-DOTATATE PET/CT for the diagnosis and management of ectopic adrenocorticotropic hormone-secreting tumours. Clin Endocrinol 2019;91:288-94.
62. Ceccato F, Cecchin D, Gregianin M, Ricci G, Campi C, Crimì F, et al. The role of 68Ga-DOTA derivatives PET-CT in patients with ectopic ACTH syndrome. Endocr Connect 2020;9:337-45.

63. Loriaux DL. Diagnosis and differential diagnosis of Cushing's syndrome. N Engl J Med 2017;376:1451-9.

64. Findling JW, Nieman L, Tabarin A. Diagnosis and differential diagnosis of Cushing's syndrome. N Engl J Med 2017;377:e3.

65. Oelkers W. Diagnosis and differential diagnosis of Cushing's syndrome. N Engl J Med 2017;377:e3.

66. Goodman RL. Diagnosis and differential diagnosis of Cushing's syndrome. N Engl J Med 2017;377:e3.

67. Newell-Price J, Morris DG, Drake WM, Korbonits M, Monson JP, Besser $\mathrm{GM}$, et al. Optimal response criteria for the human $\mathrm{CRH}$ test in the differential diagnosis of ACTH-dependent Cushing's syndrome. J Clin Endocrinol Metab 2002;87:1640-5.

68. Grant P, Dworakowska D, Carroll P. Maximizing the accuracy of inferior petrosal sinus sampling: validation of the use of prolactin as a marker of pituitary venous effluent in the diagnosis of Cushing's disease. Clin Endocrinol 2012;76:555-9.

69. Sheth SA, Mian MK, Neal J, Tritos NA, Nachtigall L, Klibanski A, et al. Transsphenoidal surgery for Cushing disease after nondiagnostic inferior petrosal sinus sampling. Neurosurgery 2012;71:14-22.

70. Sakai Y, Horiba N, Tozawa F, Sakai K, Kuwayama A, Demura H, et al. Desmopressin stimulation test for diagnosis of ACTH-dependent Cushing's syndrome. Endocr J 1997;44:687-95.

71. Newell-Price J. The desmopressin test and Cushing's syndrome: current state of play. Clin Endocrinol 1997;47:173-4.

72. Colombo P, Passini E, Re T, Faglia G, Ambrosi B. Effect of desmopressin on ACTH and cortisol secretion in states of ACTH excess. Clin Endocrinol 1997;46:661-8. 